\title{
Método da Eletrorresistividade para Mapeamento do Lençol Freático no Município de Rio Claro (SP)
}

Andresa Oliva, Chang Hung Kiang, Instituto de Geociências e Ciências Exatas - UNESP

\section{Resumo}

Foram executados ensaios geofísicos pelo método da eletrorresistividade, utilizando-se da técnica de sondagem elétrica vertical (SEV) e arranjo Schulumberger, com vistas a mapear o lençol freático na Formação Rio Claro, no município homônimo. A superfície do lençol freático (NA), na área de ocorrência dessa formação, representada por sedimentos arenosos com intercalações de camadas centimétricas argilosas, está situada entre as cotas $566 \mathrm{~m}$ e $669 \mathrm{~m}$, com o fluxo das águas subterrâneas orientado a partir das cotas altas (norte da área) para as cotas baixas (sul e sudoeste da área), acompanhando aproximadamente a topografia local.

\section{Introdução}

No presente trabalho utilizou-se, para a determinação do nível d'água subterrâneo (NA) da Formação Rio Claro, no município de Rio Claro (SP), o método da eletrorresistividade, através da técnica de sondagem elétrica vertical (SEV).

O método da eletrorresistividade baseia-se na determinação da resistividade elétrica dos materiais que, juntamente com a constante dielétrica e a permeabilidade magnética, expressam fundamentalmente as propriedades das rochas (Davino, 1970).

A técnica de SEV é muito empregada em situações onde se deseja investigar, em detalhe, os diferentes tipos e situações geológicas no subsolo, determinando suas espessuras, profundidades e resistividades.

Um dos motivos da utilização desta técnica para a elaboração do mapa potenciométrico do município de Rio Claro, foi a escassez de dados de poços perfurados na Formação Rio Claro, pois este aqüífero vem sendo pouco explorado na região. Além disso, a utilização desta técnica, que consiste em um método indireto de investigação, resultou em um mapa potenciométrico bastante detalhado da área investigada.

Foram executadas 139 SEV's na Formação Rio Claro, constituída basicamente por sedimentos arenosos, esbranquiçados e amarelados, por vezes intercalados por camadas centimétricas argilosas.

Esta unidade encontra-se assentada sobre a Formação Corumbataí, constituída por arenitos muito finos, siltitos, lamitos, folhelhos, nas cores cinza, creme, verde claro ou lilás.

A partir da técnica de SEV, o parâmetro resistividade identificou com boa precisão, os sedimentos arenosos não saturados e os sedimentos arenosos saturados da Formação Rio Claro, bem como os sedimentos da Formação Corumbataí.
Os sedimentos arenosos não saturados da Formação Rio Claro apresentam altos valores de resistividade; já os sedimentos da Formação Corumbataí apresentam resistividades baixas, graças a seus sedimentos mais argilosos.

\section{Metodologia/ Problema Investigado}

Os 139 ensaios geofísicos realizados no município de Rio Claro, foram executados através do método da eletrorresistividade, utilizando a técnica de SEV, e arranjo Schulumberger, para determinação do nível d'água subterrâneo.

O método da eletrorresistividade está centrado na capacidade do equipamento de introduzir uma corrente elétrica no subsolo, a diferentes profundidades de investigação, e medir as resistividades dos materiais geológicos nestas profundidades (Braga et al., 1998).

A grandeza que se obtém constitui a resistividade aparente $\left(\rho_{a}\right)$, pois representa a média ponderada de todas as resistividades verdadeiras de um volume relativamente grande de material em subsuperfície. Isso deve-se ao fato de que, na prática, o subsolo não pode ser considerado um meio homogêneo.

A técnica de SEV fundamenta-se na análise e interpretação das respostas do campo elétrico gerado no subsolo por eletrodos colocados na superfície do terreno, através dos quais é aplicada uma corrente elétrica.

Já o arranjo Schulumberger consiste de quatro eletrodos que são cravados na superfície do terreno, sendo apenas dois eletrodos deslocados (eletrodos A e B). Estes eletrodos têm a função de gerar corrente elétrica no terreno, enquanto que o outro par é utilizado para medir a diferença de potencial que se estabelece entre eles (eletrodos M e N) (Figura 1).

Para aumentar a profundidade de investigação, separamse os eletrodos A e B progressiva e simetricamente ao centro $\mathrm{O}$.

De um modo geral, nas sondagens elétricas, os espaçamentos utilizados entre os eletrodos de emissão de corrente $(A B)$ e os eletrodos de recepção de potencial $(\mathrm{MN})$ foram os seguintes:

-AB/2-1,5-2,0-3,0-4,0-5,0-6,0-8,0-10,0-12,0-14,0-16,020,0-25,0-30,0-40,0-50,0-60,0-80,0 e 100,0 m.

-MN/2- 0,30-2,0-5,0 e 10,0 m.

Os dados de resistividade aparente obtidos no campo, em cada SEV, foram representados por meio de uma curva bilogarítimica, em função das distâncias entre os eletrodos correspondentes (AB/2). 


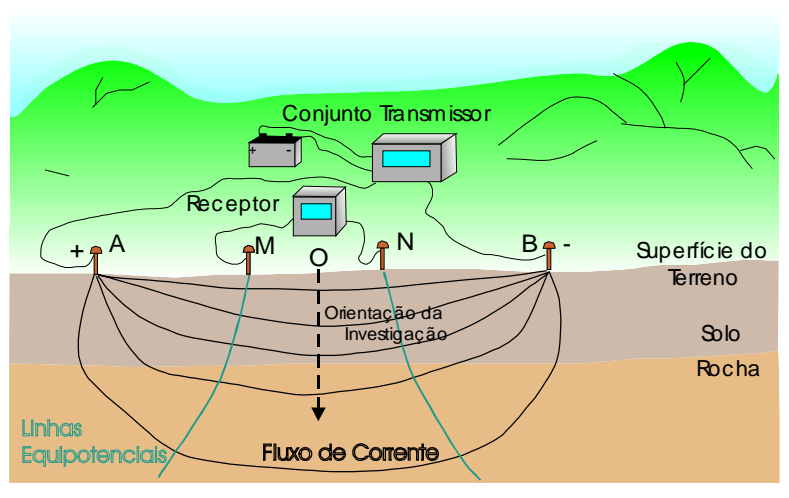

Figura 1 -Disposição dos circuitos de emissão e recepção da técnica de SEV - Arranjo Schlumberger (modificado de Braga, 1997).

\section{Resultados}

A partir da suavização e análise da morfologia das curvas de campo, gerou-se um modelo geoelétrico inicial.

Esse modelo geoelétrico inicial foi refinado, utilizando o software Resix/IP, versão 2,00 (1993), produzido pela INTERPEX LIMITED (USA), que resultou em novos modelos geoelétricos, através da inversão dos dados de resistividade obtidos nos ensaios de campo. Esse programa, através da inversão, fornece um modelo que se ajusta perfeitamente à curva de campo.

Essas interpretações possibilitaram determinar o nível d'água subterrâneo (NA) e a distribuição espacial da resistividade no subsolo, visando gerar um mapa potenciométrico da Formação Rio Claro.

Com relação à resistividade, foi possível identificar dois tipos litológicos principais na Formação Rio Claro. O primeiro com valores de resistividade altos, típicos de sedimentos predominantemente arenosos, associados à Formação Rio Claro. O segundo tipo com valores de resistividade baixos, associados aos siltitos e argilitos da Formação Corumbataí.

Em alguns casos, ocorre um terceiro tipo, com resistividade elevada, devido à presença de soleiras de diabásio (Figura 2).

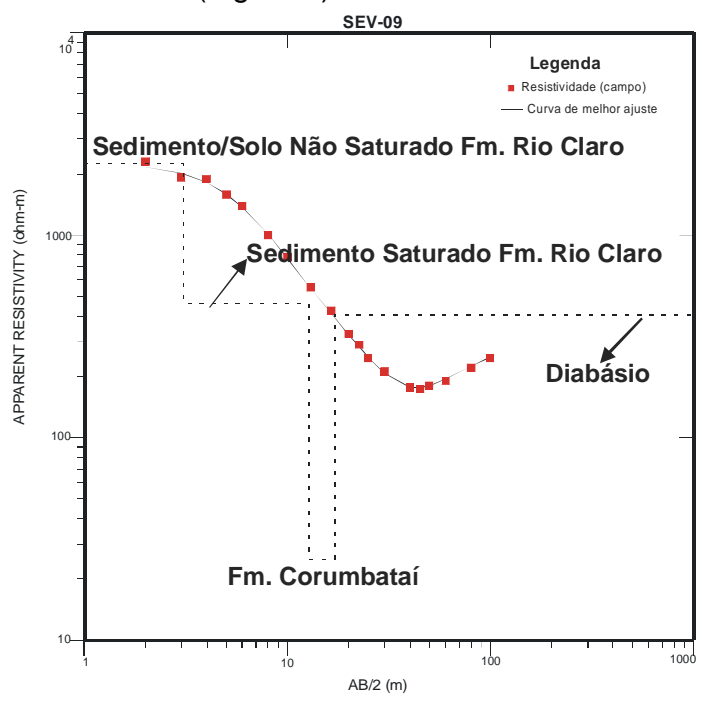

Figura 2 -Camadas geoelétricas, representando diferentes tipos litológicos.
Na própria Formação Rio Claro, é possível identificar dois estratos geológicos principais, com ampla variação de resistividade de um local para outro. Por este motivo, não seria plausível delimitar intervalos de resistividade para esses estratos.

O primeiro estrato corresponde ao solo/sedimentos não saturados da Formação Rio Claro, com altos valores de resistividade. $O$ segundo estrato é caracterizado pelos arenitos inconsolidados da Formação Rio Claro, saturado de água.

Dessa forma, nas áreas de ocorrência da Formação Rio Claro, os perfis geofísicos obtidos pelas sondagens elétricas (SEV's) definiram as seguintes camadas geoelétricas:

1. Solo/Sedimento não saturado;

2. Arenitos inconsolidados saturados;

3. Formação Corumbataí.

A espessura da Formação Rio Claro, identificada através dos perfis, varia consideravelmente de um local para outro, sendo que sua espessura diminui da área norte, onde se encontra o distrito de Ajapi, no qual várias sondagens elétricas não atingiram o topo da Formação Corumbataí, para sul, onde sondagens elétricas atingiram não só a Formação Corumbataí como as soleiras de diabásio.

O mapa potenciométrico foi confeccionado utilizando profundidades do lençol freático (NA), obtidas através da geofísica.

Conhecendo as altitudes de cada SEV, através do mapeamento com GPS diferencial de alta precisão, e a profundidade do nível d'água, é possível determinar a cota do lençol freático em cada sondagem, em relação ao nível do mar. Posteriormente, são traçadas as isolinhas do NA, gerando o mapa potenciométrico. As direções preferenciais do fluxo d'água subterrâneo são indicadas por setas.

A superfície do lençol freático (NA) está situada entre as cotas $566 \mathrm{~m}$ e $669 \mathrm{~m}$, com o fluxo das águas subterrâneas orientado, a partir das cotas altas (norte da área), para as cotas baixas (sul e sudoeste da área), acompanhando aproximadamente a topografia local, com deflexões para sudeste e sudoeste.

Em termos de distribuição espacial, o nível d'água subterrâneo está situado entre 2,01 m (região sudoeste da área) e 25,33 m (região norte da área), sendo que entre esses valores existe uma ampla variação das profundidades, prevalecendo os níveis com profundidade inferiores a $18 \mathrm{~m}$ (Figura 3). 


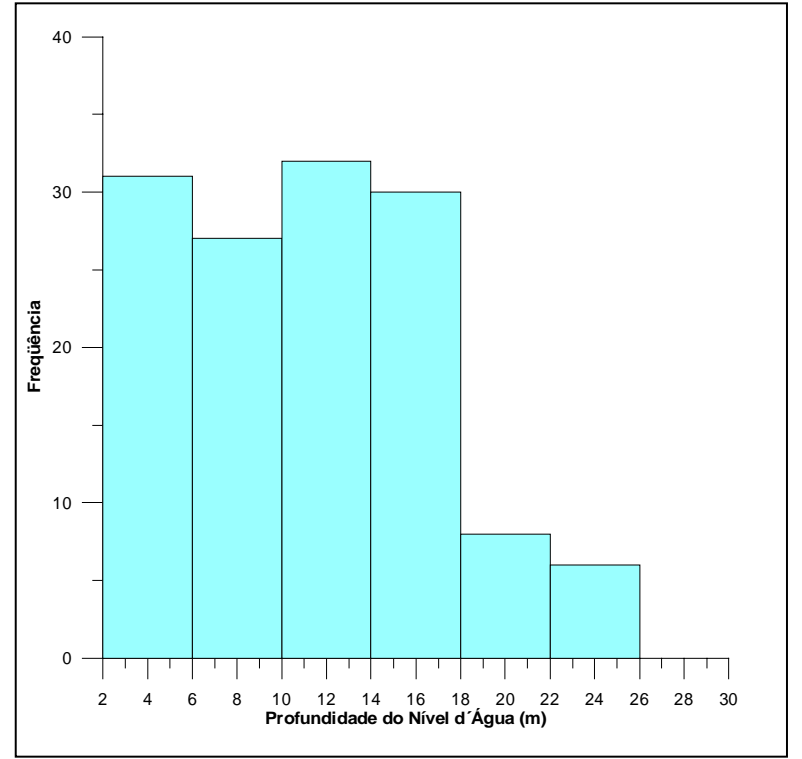

Figura 3 -Histograma ilustrando a freqüência da profundidade do NA nas sondagens elétricas verticais.

\section{Discussão e Conclusões}

A principal ferramenta utilizada para o estudo da superfície potenciométrica da Formação Rio Claro foi a geofísica, através da técnica de sondagem elétrica vertical, que forneceu valores da profundidade do nível d'água (NA), além de outros parâmetros.

Optou-se pela geofísica, em razão do pequeno número de poços instalados no aqüífero Rio Claro, pois este vem sendo explorado somente recentemente em função do aumento do consumo de água, principalmente pelas indústrias da região.

Dessa forma, seria temeroso utilizar apenas alguns poços para confecção de um mapa potenciométrico de todo município. Para caracterizar corretamente o aqüífero Rio Claro, optou-se, então, pelo adensamento de sondagens elétricas em toda a Formação Rio Claro.

A superfície do lençol freático (NA), na área de ocorrência da Formação Rio Claro, está situada entre as cotas $566 \mathrm{~m}$ e $669 \mathrm{~m}$, com o fluxo das águas subterrâneas orientado de norte para sul, com deflexões para sudeste e sudoeste (Figura 4).

Em termos hidrogeológicos, a Formação Rio Claro costitui um aqüífero livre, com profundidades do nível d'água variando entre $2 \mathrm{~m}$ e $25 \mathrm{~m}$, prevalecendo níveis com profundidades inferiores a $18 \mathrm{~m}$.

Os altos potenciométricos estão basicamente distribuídos na região norte da área e funcionam como divisores de águas; posicionam-se aproximadamente paralelos aos limites da Formação Rio Claro e à superfície potenciométrica, que segue a orientação preferencial do Rio Corumbataí, a oeste da área, e do Ribeirão Claro, a leste.

Os baixos potenciométricos estão distribuídos no sul da área, onde a Formação Rio Claro apresenta pequenas espessuras e encontra-se próxima às bordas ao contato com a Formação Corumbataí.

Toda área central da Formação Rio Claro pode ser considerada globalmente como uma área de recarga, onde as águas pluviais infiltram no solo e se deslocam em subsuperfície, declive abaixo, seguindo, grosso modo, a topografia. Áreas de descarga ocorrem somente próximo ao contato da formação.

\section{Agradecimentos}

Agradeço ao Departamento de Geologia Aplicada IGCE/Unesp - Rio Claro por ceder o equipamento de geofísica, e os acessórios necessários para a realização dos ensaios.

\section{Referências}

Braga A. C. O. 1997. Métodos Geoelétricos Aplicados na Caracterização Geológica e Geotécnica - Formações Rio Claro e Corumbataí no Município de Rio Claro - SP. Inst. de Geociências e Ciências Exatas, Universidade do Estado de São Paulo, Rio Claro, Tese de Doutoramento, $169 \mathrm{p}$.

Braga A. C. O., Malagutti W. F., Dourado J. C. 1998. Métodos da Eletrorresistividade e Polarização Induzida Aplicados na Caracterização Litológica das Formações Rio Claro e Corumbataí, Município de Rio Claro - SP. Rev. Geociências, 17 (2): 591- 608.

Davino A. 1970. Importância do Método de Eletrorresistividade na Determinação da Natureza do Manto de Decomposição em Rochas Cristalinas - São Paulo, p. 99-112, (Boletim da Sociedade Brasileira de Geologia - SBG 19). 


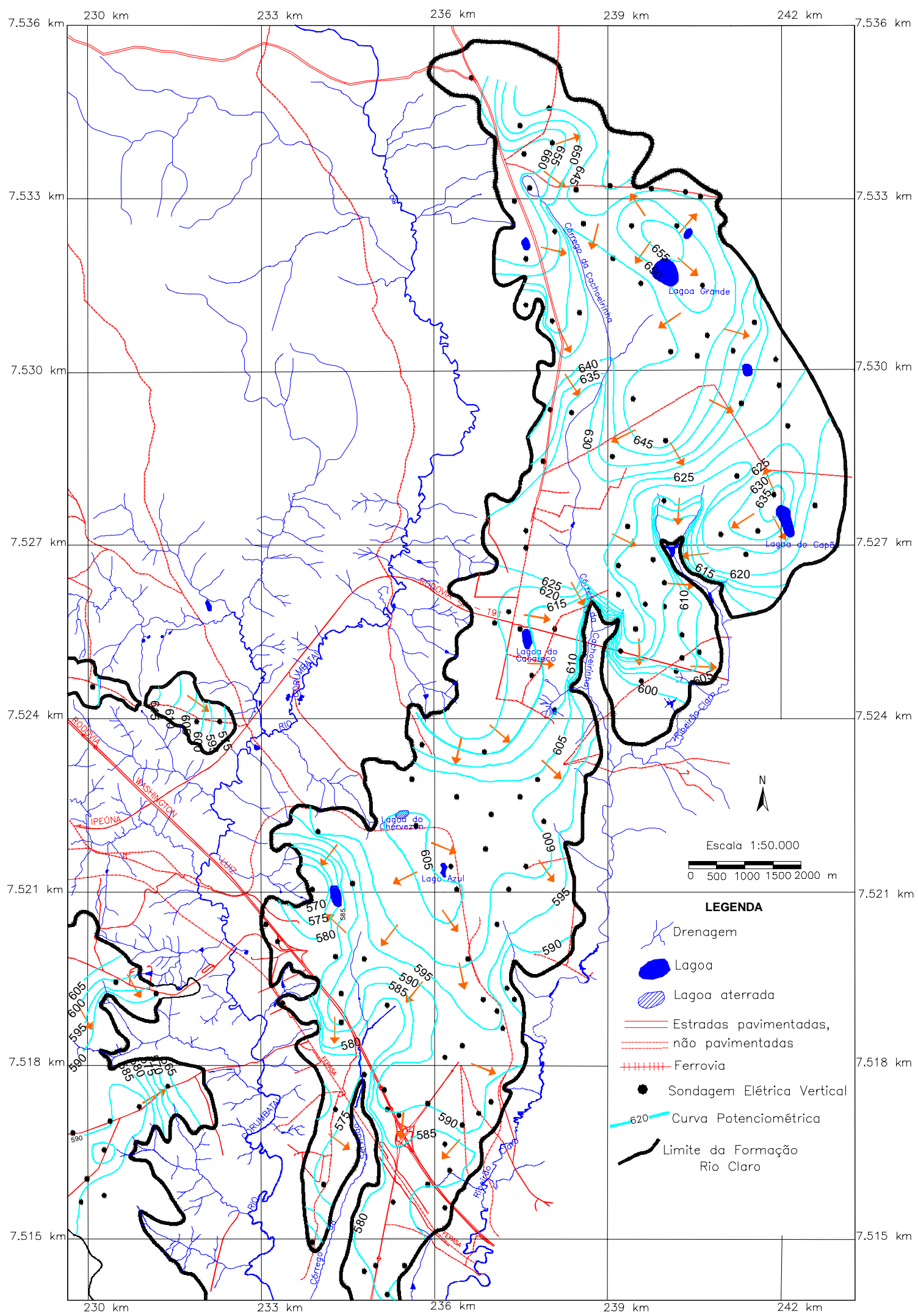

